\title{
Re-storying the Landscape: The Humanities and Higher Education for Sustainable Development
}

\author{
Nathan Hensley \\ Bowling Green State University, United States
}

\begin{abstract}
In this paper, the environmental humanities provide a lens into sustainability principles and practices within the setting of higher education. In the midst of the planetary crisis represented by the Anthropocene - the geological epoch in which human activity has become the dominant influence on the environment - the humanities can advance the sustainability movement by emphasizing the study of human experience. As we face sustainability challenges such as climate change and biodiversity loss, we encounter questions such as: what kind of education is of most value and how do we engage the environmental humanities as a mode of inquiry to better understand the crucial relationships between humans, place, and sustainability? Addressing these questions requires non-conventional modes of inquiry. Studying the stories of the landscapes that we inhabit is a non-conventional mode of inquiry that nurtures a sense of place. These stories include how the land was shaped by both natural and human forces. Stories of place and the history of how humans have altered it provide crucial insight into the human-Earth relationship. The study of place cultivates interest in infusing lived and felt human experience into the curriculum and pedagogy. Infusing human experience into higher education pedagogy encourages the linking of the sciences with the humanities. These ideas were implemented in a case study in which a swamp located in northwestern Ohio was used to contextualize sustainability education at Bowling Green State University. Such an education-oriented response to the sustainability crisis allows us to formulate new modes of inquiry, to better collaborate across disciplines, and to embrace uncertainty.
\end{abstract}

Keywords: Higher education for sustainable development, environmental humanities, sustainability, curriculum studies, curriculum theory, anthropocene

\section{INTRODUCTION}

Landscape, in other words, shapes mindscape. (Orr, 1992, p. 130)

In this time of accelerating environmental disequilibrium coupled with the rapid decrease in human-nature interaction, we need to lean into the power of story. When we learn the stories of the landscapes that we inhabit, we are better positioned to protect our places. It is important that we learn the narratives of what has shaped our landscape because this knowledge enables us to mitigate further negative anthropogenic impact. Also, stories can illuminate the fundamental interdependence and interconnectivity that exist in human, ecological, and eco-social systems. For example, stories acquired from traditional ecological knowledge emerge from over hundreds or thousands of years of direct contact between indigenous peoples and the environment (US Fish \&

*Correspondence: nhensle@bgsu.edu

Artiklar och reflektioner är kollegialt granskade. Övriga bidragstyper granskas av redaktionen. Se https://hogreutbildning.se ISSN 2000-7558

(C)2020 Nathan Hensley. This is an Open Access article distributed under the terms of the Creative Commons Attribution-NonCommercial 4.0 International License (https://creativecommons.org/licenses/by-nc/4.0/), allowing third parties to share their work (copy, distribute, transmit) and to adapt it, under the condition that the authors are given credit, that the work is not used for commercial purposes, and that in the event of reuse or distribution, the terms of this license are made clear.

Citation: Hensley, N. (2020). "Re-storying the Landscape: The Humanities and Higher Education for Sustainable Development», Högre utbildning, 10(1), 25-42. https://doi.org/10.23865/hu.v10.1946 


\section{Nathan Hensley}

Wildlife Service [USFWS], 20II). These stories provide knowledge that can only be gained through direct experience over time. Places and their stories are inherently pedagogical. The changes that take place in a landscape over time lead us to ask what else - other than landscape - can shape mindscape? Answering this requires the careful study of lived experience, place, and people.

As a curriculum theorist, I grapple with how to address crises of mind while researching the intersection of place, education, and sustainability. I have found that the environmental humanities uniquely connect aspects of curriculum studies, place studies, and sustainability studies. The environmental humanities are "a wide-ranging response to the environmental challenges of our time," (Rose et al., 20I2, p. I) and they are a way of integrating forms of inquiry from different fields to generate new ways of navigating environmental problems (University of California, Los Angeles [UCLA], n.d.). The environmental humanities are a "diverse and emergent field of cross-disciplinary research that seeks to analyze and investigate the complex interrelationships between human activity and the environment, understood in its broadest sense" (The Oxford Research Centre in the Humanities [TORCH], n.d.). More generally, the environmental humanities provide a means to analyze and study how human activity shapes the world around us, which situates scholars to embrace the primacy of human experience while cultivating sense of place for shaping curriculum and pedagogy.

Currently, I live in the Great Black Swamp, a bioregion in northwestern Ohio, in which human impact on the landscape is prolific. Before the swamp was drained, developed, and settled in the late igth century, it was an arduous landscape through which to travel. The muck of the swamp combined with densely-grown forests and clouds of mosquitoes made it an unwelcoming landscape. The decision to drain the swamp was made from a mindset entrenched in economic gain, human comfort, and agricultural freedom. After draining the swamp, the remaining landscape, flat as a pancake, provided rich farmland. As an academic in the middle of the Great Black Swamp, I utilize this place to explore human interaction with the land and as an integrating context to understand the intersections between stories, ways of knowing, and advancing the sustainability movement. Later in this manuscript, I outline a project that took place in the Great Black Swamp, designed to cultivate sense of place and build place-based education skills amongst faculty members at Bowling Green State University. The history of the landscapes that we inhabit is easily overlooked because of rapid and rampant development. In the context of sustainability, re-storying place - which involves using story to advance ecological sustainability - is a holistic, experiential, and pragmatic effort to cultivate a mutually-beneficial human-Earth relationship through understanding the narratives of interdependence and the value of the complex interrelationships that exist between the biotic and abiotic systems of a bioregion. The re-storying of our landscape is a crucial aspect of humanities-oriented sustainability education. The humanities "explore the past and present of human culture so we can understand ourselves - and create a better world for the future" (Humanities at ASU, n.d.). Narrative is one of the many modes of inquiry used in humanities scholarship. To understand these relationships and interdependencies it helps to learn the scale and history of human impact on the environment. In this paper, the environmental humanities are leveraged within the context of story, to elucidate sustainability principles and practices within the setting of higher education.

\section{STRUCTURE AND APPROACH}

In this paper, I utilize stories as a tool to integrate the environmental humanities and higher education for sustainability in curricular development, by linking narratives of human experience to actual places and changes in landscapes. The method is theoretical reflection and synthesis, 
based on curriculum theory and self-reflection and experiences from a case study. Through direct links made with specific landscapes, the self-reflective portion of this article highlights the value of humanistic investigations of place and how lived experience shapes one's sense of place.

This article utilizes multiple story threads to weave together the power of narrative, sustainability, and the humanities. The first thread reveals how stories connect people to place and cultivates ecological thinking. The next shows how an ecologically-grounded curriculum, focusing on interrelationships and interdependencies, must integrate the sciences with the humanities, arguing that these complement each other while extending their scope of relevance. The third thread illustrates how higher education for sustainability needs the humanities. These threads are then woven together in a case study that highlights how a natural region in northwestern Ohio teaches faculty members about place-based education situated in the humanities. The case study elucidates sustainability principles while demonstrating the broad applicability of place across all disciplines. The final part of the paper weaves a tapestry which indicates the power of ecological, experiential, and transformative knowledge to transmute curriculum and pedagogy. This transformation includes the forming of new modes of inquiry, collaborating better, and embracing uncertainty.

\section{STORIES AND SUSTAINABILITY EDUCATION}

It's all a question of story. We are in trouble just now because we do not have a good story. We are in between stories. (Berry, 1978, p. I)

I have been in the field of Curriculum Studies for over a decade and, as the field continues to advance, I have explored place-based education (Hensley, 20II), sustainability studies (Hensley, 2016, 2017), the role of the trickster in education (Hensley, 2018a), and mindfulness in education (Hensley, 20I8b, 2020). Through my work in curriculum studies and ecological education, I have found that the environmental humanities provide an integrative framework for understanding sustainability, place, and environmental education. Here I explore the role of the stories in the sustainability movement. Humans have left an ever-expanding ecological footprint on the planet through exploitive industrial activity and extractive land-management practices (Steffen et al., 20I5; Rockström et al., 2009). The sustainability challenges we face, such as rapid loss of biodiversity, exponential human population growth, global pandemics, and loss of a sense of place and a sense of self, are a call to action which requires a multidisciplinary response grounded in understanding the stories that shape worldviews and actions (Williams, 2008).

Story is one way to reach students as they try to understand sustainability and reinhabit their places. Stories are how we make sense of our lives, appreciate the places that we inhabit, and understand the relationships and interdependencies which make up the web of life. However, as Thomas Berry states in the epigraph, we need a new story. We need a story that accurately portrays the link between healthy ecosystems and healthy people, and promotes the healing of vital relationships. David Orr posits, "Without exaggeration it will come down to whether students come through their formal schooling as more clever vandals of the Earth and of each other or as loving, caring, compassionate, and competent healers, restorers, builders, and midwives to a decent, durable, and beautiful future." (Orr, 20I8, p. ix). An emphasis on human experience provides a map to this decent, durable, and beautiful future. Orr (2018) warns that "We won't nurture compassionate healers and restorers, if we continue to be the same people that have vandalized our Earth." (p. ix). Stories enable students to uncouple 


\section{Nathan Hensley}

from unsustainable worldviews and make sense of the ecological crisis. Stories help students acknowledge the human role in the ecological crisis and empower students to initiate the process of generating sustainable solutions.

Constructing sustainable stories requires balance between multiple perspectives and multiple disciplines. Therefore, sustainable stories necessitate integrative thinking and integrated knowledge. Will Steffen et al. (2018) state that:

Addressing [sustainability] questions requires a deep integration of knowledge from biogeophysical Earth System science with that from the social sciences and humanities on the development and functioning of human societies. Integrating the requisite knowledge can be difficult, especially in light of the formidable range of timescales involved. Increasingly, concepts from complex systems analysis provide a framework that unites the diverse fields of inquiry relevant to the Anthropocene. (p. 8253)

The call for integrating the humanities with scientific research in the midst of overexploitation is becoming more urgent. Palsson et al. observe, in the context of story, that there is a "growing awareness of the extent to which human beings have been altering the global environment" (20I3, p. Io), adding that, within the predominant story, "Humanist and social science research needs to be drawn upon in order to complement natural science approaches to planetary limits and boundaries" (p. 7). Differentiating the value of scientific and humanistic inquiry, Palsson et al. observe the following:

To characterize the Anthropocene by means of quantitative data is one thing; to describe and understand how it perceives human interaction, culture, institutions, and societies - indeed, the meaning of being human - is truly another and a major challenge for the scholarly, literary, artistic, practitioner, and policy communities ... What now matters more than anything is our capacity to respond rapidly and efficiently to linked societal and environmental challenges. (2013, p. IO)

Increasing the capacity to respond to linked societal and environmental challenges is at the crux of the effort to integrate the humanities and the sciences in higher education. Sverker Sörlin (2012) argues that "our hopes are tied to the humanities" because:

[I] $\mathrm{n}$ a world where cultural values, political and religious ideas, and deep-seated human behaviors still rule the way people lead their lives, produce, and consume, the idea of environmentally relevant knowledge must change. We cannot dream of sustainability unless we start to pay more attention to the human agents of the planetary pressure that environmental experts are masters at measuring but that they seem unable to prevent. (p. 788)

Paying more attention to the human agents of the environmental crisis requires educational reconceptualization. "If humanity is the chief cause of the ominous [environmental] change, it [is] ... inevitable that research and policy will be focused on human societies and their basic functions" (Sörlin, 20I2, p. 788). Contextualizing sustainability studies within the humanities involves focusing research on human societies and their basic functions. Centering sustainability research within the humanities offers transformative potential for higher education for sustainable development (HESD). For example, the humanities encourage the prioritization of lived experience within the educational process. In an educational setting, shifting the emphasis 
from content knowledge (outcome) to the process of learning is one attribute of prioritizing lived experience and story.

In the context of prioritizing lived experience, Thomas suggests that sustainability education addresses the need for change from a pedagogical viewpoint. He emphasizes that "teaching approaches must focus on elements relating to the process of learning, rather than the accumulation of knowledge ... which provides students with the opportunities to learn to think, specifically 'how to think' rather than 'what to think"' (Thomas, 2009, p. 245). When students learn how to think, they aren't memorizing facts, they are building their problem-solving capacity and learning how to think on their feet, which is essential to tackling intractable sustainability challenges.

Additionally, the humanities help us to better understand, change, and develop our own story. Higgins observes that "The humanities help us to make sense of our inner lives and social worlds by illuminating the historical backstories, affective dimensions, and normative bearings of contemporary experience." (Higgins, 20I8, p. 264). Illuminating the affective dimensions and historical backstories of one's inner life enables one to understand what motivates her. Understanding the human-Earth connection is one part of this process and can be helpful in finding who will be pilgrims for change.

\section{THE HUMAN-EARTH CONNECTION}

One learns a landscape finally not by knowing the name or identity of everything in it, but by perceiving the relationships in it - like that between the sparrow and the twig. (Lopez, I988, p. 64)

The environmental indicators of human impact on the planet - such as climate change, biodiversity loss, and deteriorating water quality - are products of the Anthropocene, a humaninduced geological epoch that is threatening to unravel planetary ecological integrity. Faced with the Anthropocene, we encounter questions such as, what kind of education is of most value and what kind of education will allow "the students to live on" (Morris, 2008, p. 40). Addressing these questions, in the midst of the Anthropocene, requires non-conventional modes of inquiry (Hensley, 20I8). We live in unprecedented times, and as Jagodzinski (20I8) observes, there is "no part of the Earth that has not been touched by anthropogenic activity" (p. I). Largely missing from the literature pertaining to investigating and tackling wicked sustainability problems problems that appear to be intractable and "by their nature defy complete and clear solutions" (Holm, Adamson, Huang et al., 20I5, p. 982) - is the voice of the humanities (Hulme, 20II).

Palsson et al. (2013) argue that "a major effort is necessary to place the perspectives and insights of the humanities' and social sciences' perspectives and insights at the forefront" (from abstract). Altering dominant discourse through teaching the story of the Anthropocene begins by cultivating ecological literacy and showing that humanity's relationship with the natural systems of the planet is out of balance (Palsson et al., 2013). By exceeding the carrying capacity of the earth through the overextraction of natural resources combined with the objectification of nature tied to the mechanistic worldview, we are unraveling planetary life-sustaining ecological services (Merchant, 1983; Hensley, 20II; Broome, 20I2; Jackson, 1993). As we exceed the earth's carrying capacity, we are simultaneously becoming more disconnected from nature than we have ever been before. Restoring interest in lived and felt human experience is at the crux of linking the sciences with the humanities to invigorate sustainability discourse (Weber, 2013). 


\title{
30 Nathan Hensley
}

Separation between humans and our surrounding natural systems leads to social and ecological uncertainties, which require new ways of interacting with the planetary systems that sustain us. As Thomas Berry heralds, we need a new story, a story that leads to a mutually-beneficial human-Earth relationship. We need a new story because the current story does not embrace the principles of ecology inherent to a mutually-beneficial human-Earth relationship. The current story that guides our ways of knowing and modes of expression is inadequate in terms of acknowledging the interconnectedness and interdependence between humans, between humans and nonhumans, and the ecosystem services that sustain us. We must nurture the health of the land base on which we depend for our well-being.

\section{A NEW STORY FOR AN ECOLOGICAL CURRICULUM}

\author{
The landscape seemed alive because of the stories. (Lopez, I988, p. 63) \\ Environmentalism without aesthetics is merely regional planning. (Evernden, 1978, p. 20)
}

Curriculum is formed from the epistemological perspectives that individuals or groups develop over time. In other words, curriculum is a type of story emerging from experience and guided by root metaphors. Root metaphors are the meta-schemata which guide how a particular culture understands education and how groups of people choose to educate students. The current curriculum is not adequate to tackle the incredible complexity of the Anthropocene. In the midst of eco-social uncertainty, it is crucial to craft a new curriculum and a new story embedded in a narrative of reinhabitation, revitalization, and sustainability. Reinhabitation involves learning "how to live well together in a place without doing damage to others, human and nonhuman" (Gruenewald \& Smith, 2008, p. I49). The task of reinhabitation is exemplified by learning to live in harmony with one's surrounding ecological and social community and is characterized by understanding the interconnectedness between one's consumption habits and ecological integrity. Revitalization, explains Bowers (2006), brings "about a better balance between the selfsufficiency of individuals, families, and communities and the market forces of supply and demand" (p. 6). Revitalization of relationships and reinhabitation of our land are features of sustainability. Sustainability is at the forefront of the new story proposed by Thomas Berry. It is a multidimensional effort to meet the needs of this generation while not "compromising the ability of future generations to meet their needs" (World Commission on Environment and Development [WCED], 1987). The environmental, economic, and social turbulence affiliated with the sustainability crisis demands new and integrated forms of inquiry. The humanities are well-situated to consider "multiple decisions, options and solutions based upon social uncertainties and contingencies" (Holm, Adamson, Huang, 20I5, p. 990). The humanities are positioned to integrate perspectives, paradigms, and possibilities (Schubert, 1997) that are commonly overlooked in the sciences (Palsson et al., 2013).

I argue that in higher education for sustainable development (HESD), the humanities offer a creative space for generating and implementing an eco-curriculum (see also Filho \& $\mathrm{McCrea}, 2019)$. This creative space is characterized by a radically-pluralistic epistemology, transdisciplinary forms of inquiry/research, and the ability to tolerate uncertainty (Hensley, 2020). An eco-curriculum is an interdisciplinary educational orientation that emphasizes awareness and knowledge about the inherent interconnectivity and interdependence that exists between humans, and between humans and the natural world (Hensley, 20II). The humanities enable us 
to tap into the aesthetic dimensions of educational experience while uncoupling from conventional mechanistic educational approaches to navigate difficult moments with an eye towards ecological integrity, stability, and beauty (Leopold, 1966). Libby Robin (2018) indicates that the environmental humanities, "with their commitment to clarity, transparency, and plain language, add accessibility to complex problems like climate change" (p. 2). HESD needs the humanities to embrace uncertainty, formulate new modes of inquiry, and to better collaborate across disciplines. Next, I join the conversation pertaining to the humanities and HESD while developing theoretical and practical formulations for the advancement of a mutually-beneficial human-Earth relationship in the midst of the Anthropocene.

\section{WHY HESD NEEDS THE HUMANITIES}

At the risk of sounding grandiose, Earth needs the humanities. The sustainability of the humanities requires a clear articulation of the relation between our pedagogical practice and our species' ecological resilience, meaning our ability to bounce back from crisis. (Lemenager \& Foote, 20I2, p. 575)

Because of the objectivity and the tangibility of the natural sciences, most sustainability scholarship is located in scientific venues. Scientists have more access to funding opportunities than most humanists and scientific knowledge seems to hold more credibility in the academic community than humanistic knowledge (Lowenthal, 2019). Resultantly, the humanities have taken a back seat to the sciences in higher education for sustainable development. However, advancing knowledge pertaining to sustainability requires the use of multiple forms of inquiry of which the scientific method is only one way of knowing. Accordingly, HESD demands multiple perspectives. Thus, falling into the epistemological trap of allowing science to monopolize sustainability discourse is not tenable. Chet Bowers (2018) observes that science is typically viewed as "higher-status knowledge" that does not embrace traditional ecological knowledge. Will Steffen et al. note that "The humanities ... have been marginal to sustainability research to date, which reflects the science-arts divide that has pervaded both the academic world and much of policy, legislation and management for many decades" (as cited in Castree, 20I8, p. 255). Leveraging the humanities is essential to advance and amplify sustainability education efforts across HESD. The humanities embrace deep reading as one mode of knowledge production while valuing human experience as a means to gain understanding of our world.

As John Weaver (20r8) points out, "It is the humanities that will connect science to meaning" (p. 5). To understand the relationships embedded within the web of life, we need the humanities to open up pathways of understanding. Bruno Latour maintains that it "is impossible to understand what is happening to us without turning to science," adding that "the sciences are now and will remain from now on so intermingled with the entire culture that we need to turn to the humanities to understand how they really function" (as cited in Weaver, 20I8, p. 5). The humanities allow us to weave together multiple stories while enabling access to new vantage points for knowledge acquisition. Jeffrey Kripal suggests that the humanities "bring a more expansive vision to the way that human beings know their place in the world, moving beyond empirical and historical data to consider human perception and experience" (as cited in Livingstone, 2019, p. 457). By considering human perception and experience as elemental to understanding sustainability, the humanities integrate the head, heart, and hands into sustainability discourse. 


\section{Nathan Hensley}

In contrast to the holistic approach, Andreas Weber (2013) maintains that modern culture has an "obsolete, mono-cultural worldview [that] is literally preventing us from understanding the deeper causes of our multiple crises" (p. 8). This mono-cultural worldview is exemplified by the overemphasis on the scientific method and the subjugation of holistic knowledge. Weber (2013) adds that one of the biggest obstacles to engaging effectively with sustainability issues is that "science, society and politics have, for the last 200 years, lost their interest in understanding actual, lived and felt human existence" (p. II). Restoring interest in lived and felt human experience is at the crux of linking the sciences with the humanities to invigorate sustainability discourse. Turning our attention to the current dominant educational paradigm provides insight into opportunity for educational change.

In the next section a grant-funded project at Bowling Green State University provides a case study for the implementation of a university-wide effort to incorporate humanities-oriented sustainability across the curriculum.

\section{THE BLACK SWAMP PROJECT}

... the spirits of a place cannot be transported or replaced. (Norris, 200I, p. 169)

Incorporating sustainability education across higher education institutions requires wellorchestrated and collaborative effort. Environmental humanities offer an integrating framework in which academic programs can advance the interface of sustainability across all disciplines. Emphasizing educational experience in higher education will shift performance indicators from product-based assessment to process-based assessment. Additionally, localizing curriculum through a place-based education model is an impactful way to incorporate interdisciplinary sustainability studies across the curriculum. In this section, the implementation of an interdisciplinary, humanities-oriented, place-based education faculty grant project highlights a practical example of meaningful sustainability education at a higher education institution.

Even with their high level of expertise, faculty in higher education typically lack the necessary knowledge on the topic of sustainability to teach about it in their classes. Many university stakeholders and academics are unaware of sustainability principles (Malone \& Truong, 20I7). This gap in knowledge needs to be addressed. Wals and Corcoran (2006) point out that, "[u]niversities ... have a responsibility to create space for alternative thinking" because students will need to learn to "cope with uncertainty, poorly-defined situations, and conflicting ... values, interests and reality constructions" (p. IO3). With the rapidly-changing and disorienting social and environmental crises facing our world, it is imperative that faculty members have access to education and training on the theory and practice of sustainability. The faculty workshop and learning community described below was an approach utilized to address this deficiency in knowledge about place and sustainability.

During the 20I8-2019 academic year at Bowling Green State University (BGSU), I served as a project director - along with two co-directors - for a National Endowment for the Humanities (NEH) grant-funded faculty training project called the Black Swamp Project. The focus of this project was to develop a unique approach to studying the environment and sustainability that connected the humanities with the natural sciences. The approach involved cultivating a sense of place in faculty via deep transformative field experiences, and developing curricular pathways for students of diverse backgrounds to acquire ecological literacy and, more importantly, to gain their own voice in the present-day problems related to sustainability. 
Sustainability served as an integrating theme, contextualized within the bioregion in which BGSU is situated (the Great Black Swamp). Sustainability was viewed as a conceptual umbrella that crosses disciplines and bridges the gap between the humanities and the sciences. Place served as both the background and the foreground for this project because faculty were encouraged to nurture their sense of place through direct encounters within their local bioregion.

The project was modeled after programs that have drawn national attention for their innovative approaches to curriculum change. These programs include the Piedmont Project at Emory University (Barlett, 2005) and the Ponderosa Project at Northern Arizona University (NAU) (Chase \& Rowland, 2004), which are curriculum development efforts that embrace the intellectual community to address global issues and local sustainability challenges. The Ponderosa Project is an "interdisciplinary faculty group effort to incorporate environmental sustainability issues into university courses with the goal of providing future citizens the education and skills necessary to achieve sustainable communities and societies" (NAU, 1998).

The Black Swamp Project differed from existing projects because it emphasized the humanities contribution to the environment and sustainability (Barlett \& Chase, 20I2). The emphasis on the humanities was informed by the natural sciences to embrace interdisciplinary dialogue and multiple forms of inquiry. Literature that explored the human-Earth relationship was assigned beforehand and discussed throughout the workshop's duration. The workshop brought the faculty together as a cohesive unit and the participants quickly recognized the strengths of multidisciplinary thinking (Fig. I). The collaborative mindset led to team-teaching initiatives and cross-disciplinary research efforts after the workshop.

The project had two major components. The first was the "Black Swamp Workshop," which was a field experience intended to build among the faculty a sense of place and an understanding of the unique ecological features of the local bioregion. This was a dialogic process that involved eleven faculty members from the sciences and humanities at BGSU. The focus of the workshop was faculty immersion and observation in the environment with the goal of faculty implementing this experience into their regular courses. Participants learned from each other, the project coordinators, and community experts.

The second step, the "Black Swamp Learning Community," was a regular series of meetings over the academic year in which the faculty members transferred the knowledge acquired in the workshop to develop curricular innovations. The project coordinators organized meetings with the goal of enabling faculty to incorporate experiential education and active-learning techniques into their courses. The faculty learning community meetings evolved into the development of courses for undergraduate students of different backgrounds to participate in humanities-based environmental studies. An outcome of the workshop and the learning community was three revised courses that incorporated sustainability within the humanities and a brand new teamtaught course entitled Sustainability (Hi)Stories.

As a result of the workshop, faculty were enabled to create sustainability-centered field experiences in their own courses. Also, as identified in the faculty project evaluations, the majority of the faculty noted that the workshop and learning community were effective in improving knowledge pertaining to sustainability and the humanities. Additionally, most faculty agreed that the workshop and learning community helped to generate a sense of community within the group. Accordingly, the Black Swamp Project was successful in achieving the initial goal of developing a unique approach to study the environment and sustainability that connected the humanities with the natural sciences. 


\section{Nathan Hensley}

The Black Swamp Project serves as an example of place-based faculty-level training that can be modified and applied to virtually any higher education setting. Perhaps the focus at other institutions would involve local rivers or streams that flow through or near the campus, or coastal areas that drain into major bodies of water like the Gulf Coast or one of the Great Lakes. The possibilities for application are broad and the opportunities for advancing humanitiesbased sustainability education are only limited to the bioregional imagination (Lynch, Glotfelty, \& Armbruster, 20I2) of those invested in improving humanities education across the curriculum. An education-oriented and humanities-grounded response to the sustainability crisis allows us to formulate new modes of inquiry, to better collaborate across disciplines, and to embrace uncertainty.

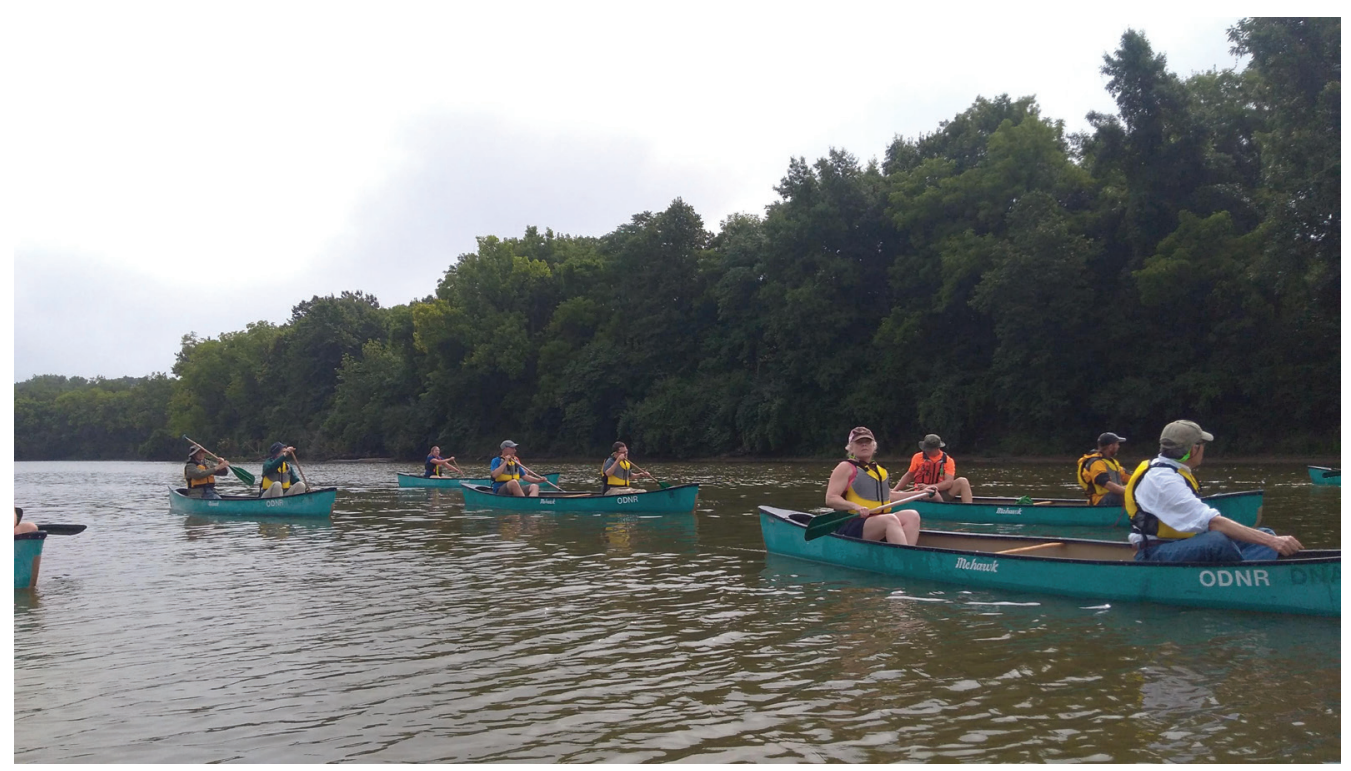

Fig. I. Black Swamp Workshop participants canoeing on the Maumee River (Photo by Nathan Hensley)

\section{THE CONTRIBUTION OF THE HUMANITIES TO SUSTAINABILITY EDUCATION}

\section{Formulating new modes of inquiry}

In a multitude of different ways, we seek to subdue the Earth to our own ephemeral purposes, considering this the proper human relationship to the natural world. (Berry, 20Io, p. 46)

Integrating sustainability and the humanities across the curriculum enables the formulation of new modes of inquiry. The investigative possibility of humanities-oriented inquiry is as expansive and diverse as the range of human experience. In the context of HESD, forging new modes of inquiry is essential to tackle the ever-evolving range of sustainability challenges. Accordingly, the divergent thinking associated with new forms of inquiry opens new pathways to tackling sustainability challenges. As Hensley (2018) indicates, 
Sustainability issues do not interface well with traditional convergent thinking (or tame/technical problems). Thusly, promoting divergent thinking is central to sustainability education. Divergent thinking is "thinking that develops in many directions." This opens possibilities because it "leads you to look at options that aren't necessarily apparent at first" (Bernhard, 2013, n.p.). When used well, the [humanities] embolden divergent thinking and facilitate deeper understanding of the inherent interconnectivity and interdependence that exists within the living world. (p. 6ro)

Looking at options that are not apparent at first expands possibilities to address sustainability issues pragmatically and rapidly. In the Black Swamp Project, the focus on interdisciplinary conversations and active learning encouraged participating faculty members to formulate new modes of inquiry pertaining to course development. For example, the workshop deliberately linked perspectives from the humanities, the social sciences, and the natural sciences to cultivate pluralistic curriculum development linked to sustainability. Libby Robin (2018) emphasizes that "By moving beyond traditional disciplinary methods, and using experiential learning performance, art and narrative, the environmental humanities extend collaborative practice beyond science and the academy" (p. 2). Extending collaboration beyond science and the academy cultivates the kind of thinking and action that can tackle seemingly-intractable problems such as climate change and algal blooms. In the workshop, through telling the story of the Great Black Swamp, presenters merged natural history with geology and cultural history while immersing participants in the themes of water quality, land use, and restoration. The culminating learning exercise was a canoeing experience on a local river which included water-quality monitoring (Fig. 2). Water-quality monitoring is one way to learn the story of a watershed because it illuminates stories about stormwater runoff and water pollution. Accordingly, direct experience brought together and enlivened the workshop content in a way that nothing else could. The competence to formulate new modes of inquiry is developed and enhanced through direct experience, as is the ability to collaborate across disciplines.

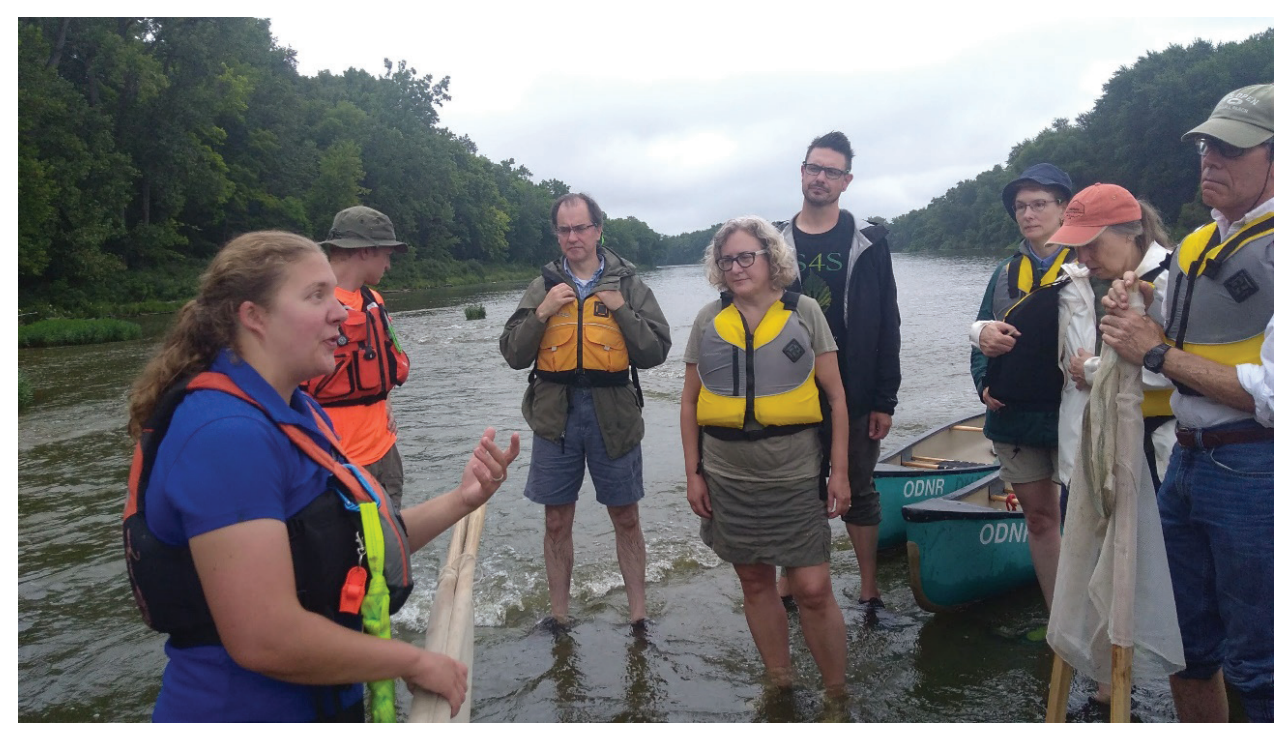

Fig. 2. Black Swamp Workshop participants learn about water-quality testing on the Maumee River (Photo by Nathan Hensley) 


\section{Nathan Hensley}

\section{To better collaborate across disciplines}

The demand for young professionals who possess both a wealth of knowledge in one system and the ability to perform cross-disciplinary collaboration is currently growing in importance in today's workforce. (Conley, Foley, Gorman, Denham \& Coleman, 20I7, p. I)

... a pluralism of perspectives can be a driving force for reaching solutions to sustainability issues in higher education. (Weakland \& Corcoran, 2009, p. 153)

In terms of understanding sustainability and being able to formulate sustainable solutions, it is essential to develop competence in interdisciplinary communication. This requires the ability to "learn the 'language' of another expertise without having to master all the disciplinary methods and practices [within a given group]" (Gorman in Conley et al., 20I7, p. 2). The ability to learn the language of other areas of expertise is referred to as "interactional expertise" (Brown, as cited in Conley et al., 2017, p. 2). Interactional expertise is the "ability to talk enough of the language of another discipline to communicate effectively" (Gormon in Conley et al., 20I7, p. 4). As a curriculum theorist, I am an interdisciplinary interloper, and I have found that being able to listen well to the stories generated from multiple academic disciplines is foundational to advancing sustainabilityrelated work. This is true because sustainability is inherently interdisciplinary and requires the ability to listen well to others and, perhaps more importantly, to make crucial connections between disciplines. This includes the ability to understand the limits of disciplinary knowledge and to learn how these limitations can be dissolved through well-orchestrated collaboration. Also, being able to tell the story of the interrelationships between disciplines is key to sustainability discourse. In the Black Swamp Project, providing the space for open dialogue and cultivating interdisciplinary perspectives was fundamental to the project's design. We frontloaded the workshop by articulating the backgrounds of the project directors. We told the story about how we conceived of the project and asked faculty what would enable them to freely share their unique disciplinary perspectives while embracing the multiple ways of knowing available within the group. Also, team-building exercises allowed participants to practice interdisciplinary problem-solving (Fig. 3).

Teaching interactional expertise at the university level involves giving students experience communicating in multidisciplinary settings and guiding them through the process of exchanging ideas across disciplinary boundaries. Improving interactional expertise requires experience learning the stories of other disciplines while gaining strategies to contribute relevant knowledge. This interdisciplinary exchange arena is referred to as a "trading zone." Trading zones provide intellectual space to tackle complex sustainability problems. Integrating the humanities with sustainability education promotes interdisciplinary communication because it enables new modes of inquiry while embracing uncertainty and opening new knowledge vistas. An increase in sustainability knowledge is more likely to happen when one is situated to embrace uncertainty.

\section{Embracing uncertainty}

The eyes of the future are looking back at us and they are praying for us to see beyond our time. They are kneeling with hands clasped that we might act with restraint, that we might leave room for the life that is destined to come. To protect what is wild is to protect what is gentle. Perhaps the uncertainty we fear is the pause between our own heartbeats, the silent space that says we live only by grace. Wild mercy is in our hands. (Williams, 200I, p. 215)

... storytelling can reveal a wider spectrum of what it means to be human than can the common, default register of the academic, authorial voice. (Greenwood, 2017, p. 255) 


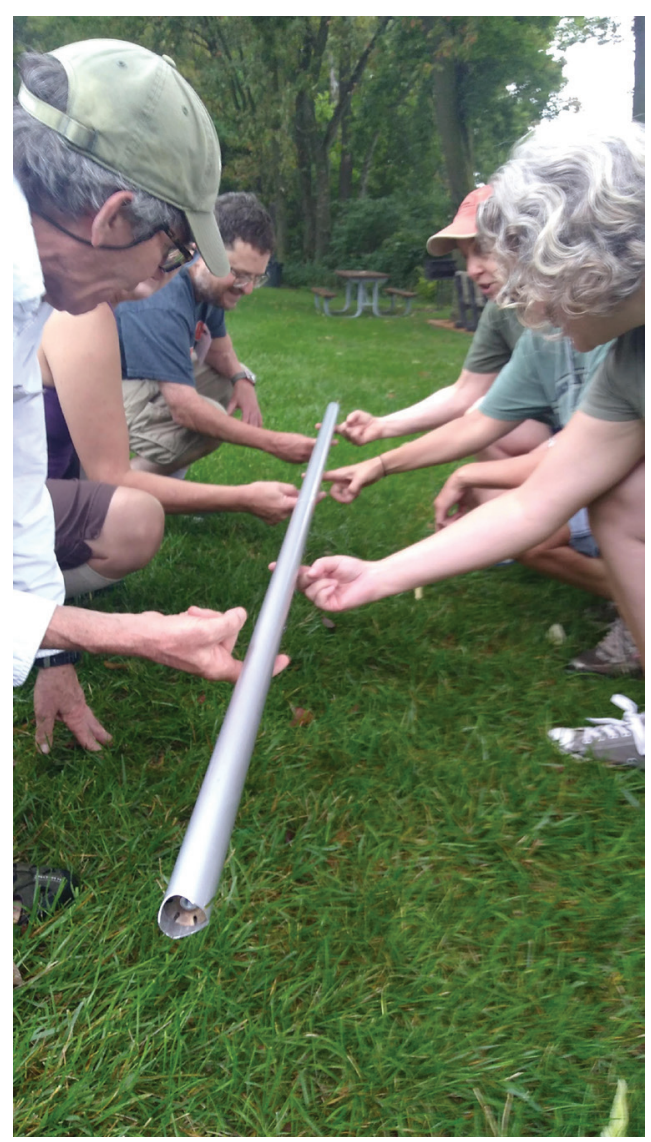

Fig. 3. Outdoor team-building activities such as this one, called Helium Stick, held during the Black Swamp Workshop promote interdisciplinary dialogue and collaboration (Photo by Nathan Hensley)

By helping to shift paradigms and alter worldviews, the humanities enable us to cultivate a heuristic to handle the unknown and to better deal with the multiplicity of sustainability challenges that characterize the Anthropocene. Handling sustainability challenges well requires mental flexibility, which is characterized by being able to handle unexpected situations, adapting to new situations, and the capacity to discover unexpected links between areas of study. Discovering links between disciplines enables scholars to foster transdisciplinary work.

The ability to embrace disciplinary overlap needs to be facilitated among students and professionals. Scholars Clark and Button argue that the "role of the arts is essential in promoting critical inquiry of environmental awareness and sustainability" (20II, p. 42). Furthermore, the arts "promote cultural change, trigger the imaginative conscience and community action and act as a bridge towards scientific understanding and application of sustainable efforts" (Minor, as cited in Clark \& Button, 20I2, p. 43). Using the humanities to trigger imagination (and hence, creativity) while building a bridge between scientific and humanistic understanding is at the crux of connecting education and sustainable development. When the humanities are interlinked with the natural and social sciences, we can view sustainability issues more accurately and allow sustainable 


\section{Nathan Hensley}

development to move to the forefront of interdisciplinary dialogue across the academy (Hensley, 20I2; 20I7; 2020). By "integrating seemingly incommensurate disciplines, a new type of [scholar] will be equipped with the necessary skills to solve 'real world' problems, which are not confined to a single discipline" (Conley et al., 20I7, p. 166). According to Hensley (2020), this new type of scholar "will be able to comfortably work between disciplines and tolerate uncertainty when pushing the boundaries of their own disciplinary knowledge" (p. 4). At the workshop, participants participated in a design thinking session to facilitate brainstorming related to wicked problems occurring in higher education (Fig. 4).

Since it is essential to cross-disciplinary work, the Black Swamp Project cultivated a posture of mental flexibility through the exploration of different perspectives and the fostering of new paradigms. Accordingly, the Black Swamp Project required participants to embrace uncertainty in the formulation of new perspectives, new forms of inquiry, and collaboration across disciplines. Since the future is unknown, it is the capacity to tolerate uncertainty and "stay with the trouble" that serves as a lynchpin for open sustainability discussion and sustainability education (Haraway, 20I6). Since the humanities allow us to study and embrace human experience, it is the humanities that will best allow HESD to develop a level of comfort with the unknown necessary to connect different ways of knowing, formulate new forms of inquiry, and thrive in uncertain times.

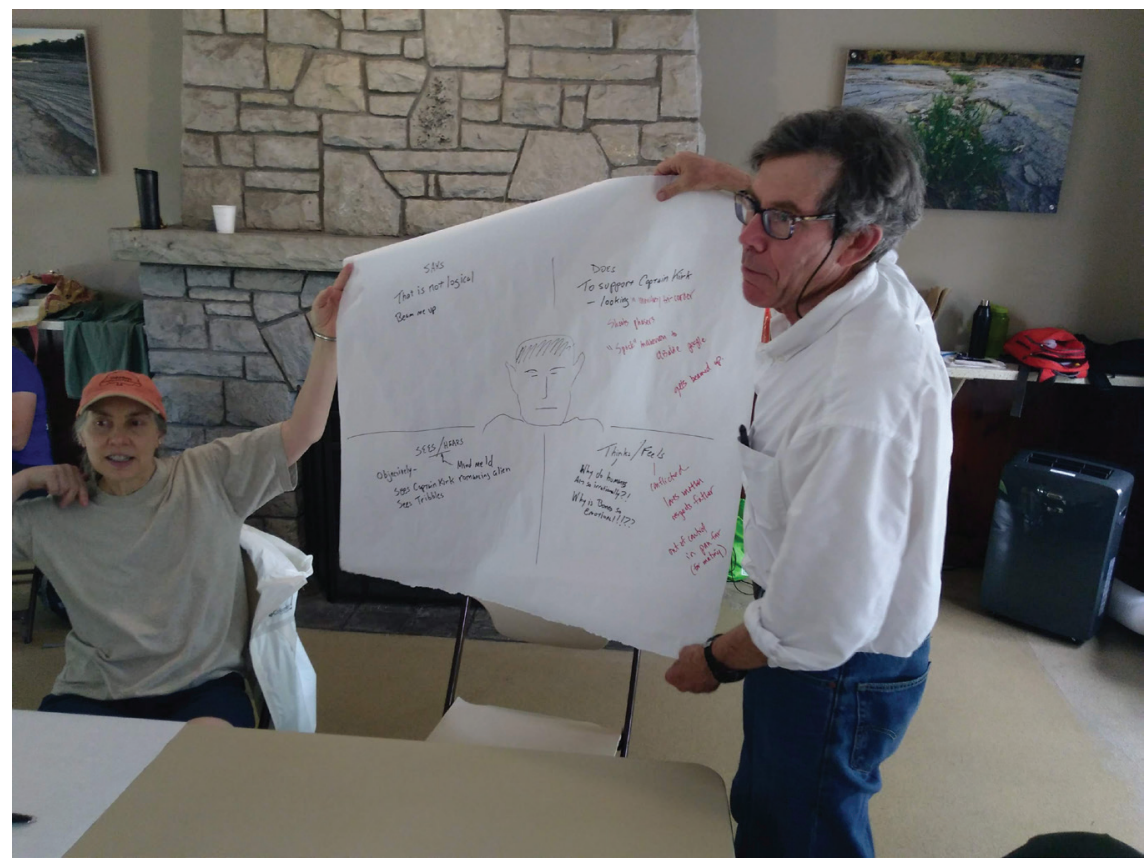

Fig. 4. Black Swamp Workshop participants engage in a design thinking session focusing on embracing uncertainty and tackling interdisciplinary problems (Photo by Nathan Hensley)

\section{CONCLUSION}

The environmental humanities provide an integrated framework to explore educational questions that are interlinked with the rise of the Anthropocene. This integrated framework offers a creative space for generating and implementing an eco-curriculum, a curriculum that embraces 
interconnections and interdependencies through holistic interactions with the bioregions in which we live. Also, the environmental humanities catalyze the aesthetic dimensions of educational experience, while uncoupling from mechanistic educational approaches, to navigate difficult moments. By using stories to connect the conversations pertaining to the environmental humanities we can articulate theoretical and practical formulations for the advancement of mutually-beneficial human-Earth relationships in the midst of the Anthropocene. The environmental humanities offer HESD a framework for integrated and pragmatic implementation of sustainability education that allows us to see beyond our time while crafting solutions to difficult sustainability problems.

\section{ABOUT THE AUTHOR}

Nathan Hensley is an Assistant Professor of Sustainability Education at Bowling Green State University and author of Curriculum Studies Gone Wild: Bioregional Education and the Scholarship of Sustainability. Nathan's work explores the intersections between the environmental humanities, curriculum studies, and sustainability education. He is passionate about bringing his students outdoors to build ecological literacy and cultivate sustainability and aesthetic sensibilities. He lives in Bowling Green, Ohio with his wife and two young daughters where they commonly explore the rivers, trails and wetlands of the Great Black Swamp.

\section{REFERENCES}

About the environmental humanities initiative [Arizona State University]. (n.d.). Retrieved October 7, 2019, from What are the Environmental Humanities? https://sustainability.asu.edu/environmentalhumanities/about/

Barlett, P. F. (2005). Reconnecting with place: Faculty and the Piedmont Project at Emory University. In P. F. Barlett (Ed.), Urban place: Reconnecting with the natural world (pp. 39-60). Cambridge, MA: MIT Press.

Barlett, P. F., \& Chase, G. W. (2012). Curricular innovation for sustainability: The Piedmont/Ponderosa model of faculty development. Liberal Education, 98(4), 14-21.

Berry, T. (1978). The new story: Comments on the origin, identification and transmission of values. New York: The American Tielhard Association for the Future of Man.

Berry, T. (2010). Evening thoughts: Reflecting on Earth as sacred community (M. E. Tucker, Ed.). San Francisco, CA: Sierra Club Books.

Bowers, C. A. (2018). Ideological, cultural, and linguistic roots of educational reforms to address the ecological crisis: The selected works of C.A. (Chet) Bowers. New York, NY: Routledge.

Broome, J. (2012). Climate matters: Ethics in a warming world (First edition). New York: W. W. Norton.

Castree, N. (2014). The Anthropocene and the Environmental Humanities: Extending the conversation. Environmental Humanities, 5(1), 233-260. https://doi.org/10.1215/22011919-3615496

Chase, G., \& Rowland, P. (2004). The Ponderosa Project: Infusing sustainability in the curriculum. In P. F. Barlett \& G. W. Chase (Eds.), Sustainability on campus: Stories and strategies for change (pp. 91-105). The MIT Press.

Clark, B., \& Button, C. (2011). Sustainability transdisciplinary education model: Interface of arts, science, and community (STEM). International Journal of Sustainability in Higher Education, 12(1), 41-54.

Conley, S. N., Foley, R. W., Gorman, M. E., Denham, J., \& Coleman, K. (2017). Acquisition of T-shaped expertise: An exploratory study. Social Epistemology, 31, 2, 165-183.

Diego, A. \& Diaz, E. (2018). Much more than knowledge: Virtue ethics and character education for degrowth. Conference presentation. https://www.researchgate.net/publication/328202053

Evernden, N. (1978). Beyond ecology: Self, place, \& the pathetic fallacy. The North American Review, 263(4), 16-20. JSTOR.

Filho, W. \& McCrea, A. C. (Eds.). (2019). Sustainability and the humanities. Cham, Switzerland: Springer International Publishing. 


\section{Nathan Hensley}

Greenwood, D. (2017). Telling our own stories: A provocation for place-conscious scholars. In N. Ares, E. Buendía, \& R. Helfenbein (Eds.), Deterritorializing/Reterritorializing: Critical Geography of Educational Reform (pp. 253-256). Rotterdam: Sense Publishers.

Haraway, D. J. (2016). Staying with the trouble. Durham, USA: Duke University Press Books.

Hensley, N. (2011). Curriculum studies gone wild: Bioregional education and the scholarship of sustainability. New York: Peter Lang.

Hensley, N. (2012). Beyond a carbon copy curriculum: Cultivating stewardship and awareness through sustainable education. In J. Lin \& R. Oxford (Eds.), Transformative eco-education for human and planetary survival: Environmental education in a new era (pp. 61-74). Charlotte, NC: Information Age Publishing.

Hensley, N. (2013). CIDER: An acronym for understanding the educational possibilities for bioregionalism. Journal of Sustainability Education, 4. http://www.jsedimensions.org/wordpress/wpcontent/ uploads/2013/02/NathanHensley3Winter2013PDF.pdf

Hensley, N. (2016). The SHEEEPS acronym as a framework for confronting wicked problems in times of rapid change. In Envisioning futures for environmental and sustainability education (pp. 345-356). Wageningen Academic Publishers. https://doi.org/10.3920/978-90-8686-846-9_26

Hensley, N. (2017). The Future of Sustainability in Higher Education. Journal of Sustainability Education, 13. http://www.susted.com/wordpress/wp-content/uploads/2017/03/Hensley-JSE-March-2017-FutureCasting-Issue-PDF.pdf

Hensley, N. (2018a). Transforming higher education through trickster-style teaching. Journal of Cleaner Production, 194, 607-612. https://doi.org/10.1016/j.jclepro.2018.05.116

Hensley, N. (2018b). Promoting mindfulness in education: the "SURE" approach. In Sociocultural perspectives on youth ethical consumerism (pp. 163-175). Springer. https://doi.org/10.1007/978-3-31965608-3_11

Hensley, N. (2020). Educating for sustainable development: Cultivating creativity through mindfulness. Journal of Cleaner Production, 243, 1-4. https://doi.org/10.1016/j.jclepro.2019.118542

Higgins, C. (2018). From the editor: Educational philosophy as vanguard of the public humanities. Educational Theory, 68(3), 255-267. https://doi.org/10.1111/edth.12310

Holm, Poul et al. 2015. Humanities for the Environment-A manifesto for research and action. Humanities 4(4): 977-92. https://doi.org/10.3390/h4040977

Hulme, M. (2011). Meet the humanities. Nature Climate Change, 1(4), 177-179. https://doi.org/10.1038/ nclimate 1150

Humanities at ASU. (n.d.). Humanities at ASU: Sharing the human experience. Retrieved October 9, 2019, from: https://humanities.asu.edu/

Jackson, W. (1993). Becoming native to this place. Great Barrington, MA: E. F. Schumacher Society.

Jagodzinski, J. (Ed.). (2018). Interrogating the Anthropocene. Springer International Publishing. https://doi. org/10.1007/978-3-319-78747-3

Jickling, B., Blenkinsop, S., Timmerman, N. \& De Danann Sitka-Sage, M (Eds.). (2018) Wild pedagogies: Touchstones for re-negotiating education and the environment in the Anthropocene (pp. 1-22). https:// doi.org/10.1007/978-3-319-90176-3_1

Leopold, A. C. (1966). A Sand County almanac. New York: Oxford University Press.

Lemenager, S., \& Foote, S. (2012). The sustainable humanities. PMLA, 127(3), 572-578.

Livingstone, L. (2019). Taking sustainability to heart-Towards engaging with sustainability issues through heart-centered thinking. In W. L. Filho \& A. C. McCrea (Eds.), Sustainability and the humanities (pp. 455-467). https://doi.org/10.1007/978-3-319-95336-6_26

Lopez, B. (1988). Crossing open ground. New York: Scribners.

Lowenthal, D. (2019). Quest for the unity of knowledge. New York: Routledge.

Lynch, T., Glotfelty, C., \& Armbruster, K. (Eds.). (2012). The bioregional imagination: Literature, ecology, and place. Athens: University of Georgia Press.

Malone, K., \& Truong, S. (2017). Sustainability, education, and anthropocentric precarity. In K. Malone, S. Truong, \& T. Gray (Eds.), Reimagining sustainability in precarious times (pp. 3-16). Singapore: Springer. 
Merchant, C. (1983). The death of nature: Women, ecology, and the scientific revolution. New York: Harper One. Morris, M. (2008). Teaching through the ill body: A spiritual and aesthetic approach to pedagogy and illness. Rotterdam: Sense Publishing.

National Council for Science and the Environment. (2003). Education for a sustainable and secure future. Washington, D.C.: National Council for Science and the Environment. Available: www.ncseonline. org/NCSEconference/2003conference/2003report.pdf

NAU (Northern Arizona University) Ponderosa Group. (1998). The Ponderosa Project. http://www2.nau. edu/ ponder-p/

Norris, K. (2001). Dakota: A spiritual geography. Boston: Houghton Mifflin.

Orr, D. W. (1992). Ecological literacy: Education and the transition to a postmodern world. Albany, NY: State University of New York Press.

Orr, D. W. (2018). Foreword. In B. Jickling, S. Blenkinsop, N. Timmerman, \& M. De Danann Sitka-Sage (Eds.), Wild pedagogies: Touchstones for re-negotiating education and the environment in the Anthropocene (pp. vii-x). Springer International Publishing. https://doi.org/10.1007/978-3-319-90176-3_1

Palsson, G., Szerszynski, B., Sörlin, S., Marks, J., Avril, B., Crumley, C., Hackmann, H., Holm, P., Ingram, J., Kirman, A., Buendía, M. P., \& Weehuizen, R. (2013). Reconceptualizing the 'Anthropos' in the Anthropocene: Integrating the social sciences and humanities in global environmental change research. Environmental Science \& Policy, 28, 3-13. https://doi.org/10.1016/j.envsci.2012.11.004

Pinar, W. (2004). What is curriculum theory? Mahwah, N.J: L. Erlbaum Associates.

Robin, L. (2018). Environmental humanities and climate change: Understanding humans geologically and other life forms ethically. Wiley Interdisciplinary Reviews: Climate Change, 9(1) 1-18.

Rockström, J., Steffen, W., Noone, K., Persson, A., Chapin, F. S., Lambin, E., Lenton, T. M., Scheffer, M., Folke, C., \& Schellnhuber, H. J. (2009). Planetary boundaries: Exploring the safe operating space for humanity. Ecology and Society, 14(2).

Rose, D. B., Van Dooren, T., Chrulew, M., Cooke, S., Kearnes, M., \& O’Gorman, E. (2012). Thinking through the environment, unsettling the humanities. Environmental Humanities, 1(1), 1-5. https:// doi.org/10.1215/22011919-3609940

Schubert, W. H. (1997). Curriculum: Perspective, paradigm, and possibility. Upper Saddle River, N.J.: Prentice-Hall.

Smith, G. A., \& Williams, D. R. (Eds.). (1999). Ecological education in action on weaving education, culture, and the environment. Retrieved from http://search.ebscohost.com/login.aspx?direct=true \&scope $=$ site $\& \mathrm{db}=$ nlebk\&db=nlabk\&A N=5593

Sörlin, S. (2012). Environmental Humanities: Why should biologists interested in the environment take the humanities seriously? BioScience, 62(9), 788-789. https://doi.org/10.1525/bio.2012.62.9.2

Steffen, W., Richardson, K., Rockstrom, J., Cornell, S. E., Fetzer, I., Bennett, E. M., Biggs, R., Carpenter, S. R., de Vries, W., de Wit, C. A., Folke, C., Gerten, D., Heinke, J., Mace, G. M., Persson, L. M., Ramanathan, V., Reyers, B., \& Sörlin, S. (2015). Planetary boundaries: Guiding human development on a changing planet. Science, 347(6223), 1259855.

Steffen, W., Rockström, J., Richardson, K., Lenton, T. M., Folke, C., Liverman, D., Summerhayes, C. P., Barnosky, A. D., Cornell, S. E., Crucifix, M., Donges, J. F., Fetzer, I., Lade, S. J., Scheffer, M., Winkelmann, R., \& Schellnhuber, H. J. (2018). Trajectories of the Earth System in the Anthropocene. Proceedings of the National Academy of Sciences, 115(33), 8252-8259. https://doi.org/10.1073/ pnas. 1810141115

Thomas, I. (2009). Critical thinking, transformative learning, sustainable education, and problem-based learning in universities, Journal of Transformative Education, 7(3), 245-264.

TORCH, The Oxford Research Centre in the Humanities. (n.d.). Environmental Humanities. Retrieved October 9, 2019, from The Oxford Research Centre in the Humanities website: https://www.torch. ox.ac.uk/envirohum

UCLA (University of California, Los Angeles). (n.d.). The environmental humanities at UCLA. What Is the Environmental Humanities? http://environmental.humanities.ucla.edu/ 


\section{Nathan Hensley}

US Fish \& Wildlife Service (USFWS). (2011). Traditional ecological knowledge for application by service scientists. US Fish \& Wildlife Service, 1-5. Retrieved from https://www.fws.gov/nativeamerican/pdf/ tek-fact-sheet.pdf

Wals, A. E. J., \& Corcoran, P. B. (2006). Sustainability as an outcome of transformative learning. In Drivers and barriers for implementing sustainable development in higher education, Workshop (pp. 103-108). Paris: UNESCO. Retrieved from http://unesdoc.unesco.org/images/0014/001484/148466E.pdf

Weakland, J. P., \& Corcoran, P. B. (2009). The Earth Charter in higher education for sustainability. Journal of Education for Sustainable Development, 3(2), 151-158.

Weaver, J. A. (2018). Science, democracy, and curriculum studies. Cham, Switzerland: Springer International. Retrieved from https://www.springer.com/gp/book/9783319938394

Weber, A. (2013). Enlivenment: Towards a fundamental shift in the concepts of nature, culture, and politics. Berlin, Germany: Heinrich Boll Foundation.

Williams, T. T. (2001). Red. New York: Pantheon Books.

Williams, T. T. (2008). Finding beauty in a broken world. New York: Pantheon Books.

World Commission on Environment and Development - WCED (Ed.). (1987). Our common future. Oxford: Oxford University Press. 